\title{
Investigation on the Influences of Cadential Cycles on Poetic Meter and Measure
}

\author{
Farzaneh Vaezi \\ Farhad Divsalar
}

Department of Literature, Islamic Azad University, Karaj Branch, Karaj,

Iran Email:divsalarf@yahoo.com

\section{Doi:10.5901/mjss.2014.v5n15p622}

\begin{abstract}
Music and literature have so long been regarded as inseparable entities by nations, that no real divide can be drawn between them. However, they each enjoy independence, given they arise from different sources. The human soul has intense ties with poetry and music, for the human soul is harmonious, and this oneness and harmony are cause and motive for a healthy soul. It is noteworthy that a combination of music and poetry would make for a concoction that is the very cure to the human soul. Given the firm bond between music and literature, the present thesis studies rhythmic cycles (cadential cycles) and their influence on poetic metre and measure (rhythm). Therefore, some musical and literary jargon is mentioned, namely: poetic rhythm; metric feet (rhythmic units); musical rhythm; cadence (ancient musical timing in poetry); types of cadence; elements of cadence; and cadential feet (atanin) and cycles, which make for rhythm. In addition, the thesis analyses some views of Abd-olQaadir Maraaghi* and Safi-ed-Din Ormavi, who say that cadence is a crucial part of the art of music and poetry, and that Persian meter and prosody is in fact part and parcel of the Iranian musical disposition. Furthermore, analyzing their works stresses the point that rhythm in Iranian music springs from rhythmic speech or Persian poetry, and that ancient musicologists presented musical theory on cadence, based on rhythmic elements, which connect metric (prosodic) rhythm and musical rhythm.
\end{abstract}

Keywords: Poetic rhythm; rhythmic cycles; rhythmic feet; cadence; rhythm; poetic meters.

\section{Introduction}

The interaction and relationship between music and poetry goes way back in our rich culture. No doubt this relationship began when mankind learned of the effect of music on the human psyche. Not only is such interaction deep-rooted in our rich culture; but every nation has had a stake in music, because music is inherent in human nature. Instigating factors in Man's quest for music are the same as those pushing him to recite poetry. This is a strong bond, as poetry is the music of words, and the union between poetry and music is a union between music and words.

Poetry accompanying music in Iran's rich literature and close ties between music and Iranian literature, have long been significant and have contributed to high cultural teaching standards. That is standards that demand training in correct recital and understanding of poetry, as well as methodically making a piece of music to fully express all feeling in the poem. This is because in Islamic-Iranian culture music and poetry are a unified body, acting as cultural pillars in their inseparable natures.

Over the ages, such companionship and close ties have deeply imprinted on Iranian music, so that should an artist make music piece sans lyric poetry, the void would be fully tangible. The audience would be waiting for words.

It is noteworthy that the framework of Iranian music depends on instruments, but its expression and rhythm depend on words and poems. This is in spite of the fact that poetry for its part needs rhythm and musical tunes, in order to attract and effect. This bilateral interaction is fully evident over the years.

It is also noteworthy that although music and poetry share close ties, they are from two separate and very different sources. Music is art and poetry is literature; two entities that can each contribute independently and without help from the other. These two entities when paired convey a clearer and more effective message to the audience.

This outlook led to our literary ancestors' belief in the unbreakable bond between prosodic circles and musical circles, and their frowning upon any diversion from harmony between poetic metre and measure, and musical feet, scales, modes and tunes. It was even customary for them to present their poetry in person, by song and harp to the King's court, if they had a good voice and knew how to play a musical instrument. This was so important to them that should a poet be lacking in these two skills, he would assign a narrator to the task; for poets of old had an insight as to 
the strong ties between music and poetry. They understood the topic and content of a poem and the relationship between poetic rhythm and relative scales and musical instruments; and with that understanding they made poetry musical and melodic with maximized emotional effect, be it tragic, joyous, exciting or epic, in various poetic forms such as: elegy, satire, epic, romantic or eulogy.

In all time-space arts such as music, dance, poetry, masonry, architecture and painting, there is measure and harmony; an order tangible in its various forms even in nature. A heart-beat, a dance of colours in harmonious motion from pale to dark, all possesses an order which is characteristic of rhythm. (Mallah, 1988).

What caused Art is relations between people in the outer world, because humans worked in groups and realized that only harmonious movement can reduce the stress of monotonous work; and it is rhythm in poetry and cadence (iqa) in music that can curb a scattered brain and bring energetic order to the mind. Richard, an English literary critic believes that rhythm in poetry and cadence in music is a hypnotic factor that causes lethargy and sleep, and that this hypnotic effect of poetry is usually in fluctuation due to the variety of its images. Therefore, poetry is as a dream interrupted by successive awakenings. (Mo'tamedi, 2004).

\subsection{Rhythm}

Rhythm is sensed by the ear. Should we notice that we don't sense rhythm in European poetry, we have practically accepted that rhythm springs from sensing specific symmetries or cadences. Should recurring symmetries (the cause for rhythm) be such that we cannot detect relative cadence between them, we cannot sense the rhythm. Certain rhythms need to be studied several times, before we can see cadence in their order. (Kadkani, 2012). What is certain, is that a sense of rhythm and its source may have stemmed from different roots, among different nations. For instance, Kalman Hawar believes that the source of rhythm in Arabic poetry is the footfall of camels in the desert. (Kadkani, 2012). Rhythm is in a way, ecstasy and surrender for the acceptance of reflections or hallucinations of another's mind; just as lies can be communicated in such a way that an audience will approve it. But without rhythm, this ecstasy and surrender to words emanated from the mind of another would not be so easily achieved.

Rhythm creates musical bliss, which is in human nature to inevitably enjoy. The language of emotion is always rhythmical. Rhythm regulates the level and frequency of beats and movements. It stresses certain words in every poem, and enhances their allure. (Kadkani, 1959).

Therefore, music and poetry with their cadence and rhythm, have played a great part in reducing lethargy and stress and increasing incentive and joy for life. By matching different musical tensions to short, long and stressed syllables, we can extract the musical cadence (rhythm) of words and poetry.

In regard to the relationship between poetry and music, Forsat-od-Doleh Shirazi (13 $3^{\text {th }} \mathrm{c}$, Lunar Hijrah) has said in Bohur-ol-Alhan: "As cadence has elements that rhythmic cycles are derived from, poetic rhythm has elements that give rise to metre. Sabab (guy-wire), watad (peg) and space in poetry, also exist in musical cadence."

It is noteworthy that due to the mono-sound nature of music, cadence has enjoyed considerable growth, and that beat strength and note-head colours for percussion and animal-hide instruments have played an important role in expanding the sound structure of cadences. Up until the third century Hijrah, singers and musicians followed a single pattern of cadence. But Ibrahim-ibn-AlMehdi (deceased 224 Lunar Hijrah) believed that these two [groups] must use separate time patterns and that the resulting rhythmical intertwining, would make for beautiful music.

In music, rhythm is based on metric syllabic patterns. Hence based on that, rhythmic cycles (cadential cycles) have been derived. For the purpose of scansion however, instead of the syllabic variant (Afa'il), the two letters 't' and ' $n$ ' are sometimes used in combinations such as tan, tanan, tananan, tanananan, known as Atanin. (Mallah, 1988).

In order to determine the rhythm of a poem, poets used the Atanin method rather than metric jargon. For example, to extract rhythm from the following line of verse:

Tavana bovad hark e dana bovad Ze danesh del-e pir borna bovad

(Powerful is he who has knowledge Young is an old heart that holds knowledge), instead of fa'ulon-fa'ulon-fa'ulonfa'ul, poets would chant tatantan- tatantan- tatantan-tatan, words that are particles of cadence or means of scansion to determine rhythm. (Mallah, 1983).

Rhythm is the constant repetition of the unit of speech, ie the syllable, and pronunciation is the tune of vocal cords vibrating to create that syllable, ie the morph; cause for stimulating the audience's hearing sensors and therefore emotions. These sensors run the audio input through the individual's memories, instincts and emotions, causing change in the mental and emotional state of the poetic audience. Also, among the essentials of Persian poetry are tune and tempo, which are embedded in poetic rhythm and structure, and without which Persian poetry would lose its very effectiveness. 
Rhythm is an outcome of order and proportion in pronounced sound. Rhythm is made of several syllables joined by a stress or strong beat, and the repetition of a scale/s. A scale on the other hand, is the smallest unit of rhythm.

Every line of Persian verse is a combination of several short and long syllables strung in a certain order. But all syllables in a hemistich, are not of like quality or pronunciation, because a hemistich is made of words and every word has at least one stressed syllable. So, stress is the blood-life of the word, and the syllables in a hemistich (half-line of verse) can be divided as stressed and unstressed. The measure of the hemistich is divided into parts, each part comprising several inter-related syllables, like mafa'eelon, fa'elaton and mostaf'alon. The link between the syllables constructing these parts, is the stress on the syllable 'ee' in mafa'eelon, on the third syllable 'la' in fa'elaton, and on the second syllable 'taf' in mostaf'alon. (Khanlari, 2008).

Evidently, in all poems every part has a stress, but that stress is placed differently in different parts. Stress in Persian poetic rhythm, is not a foundation of rhythm, but an organizer of parts [of verse] and a link between syllables. Every part requires at least one stress. Well-timed syllable stress, makes for beat and order in a poem's rhythm. The absence of such order will not destroy the poem's rhythm. But it will create inconsistency and changes in it. (Khanlari, 2007)

Poetic rhythm is an organized collection of short and long syllables. A short syllable must inevitably be pronounced in conjunction with the next syllable. Otherwise there would be no short syllable. For example if we review mafa'eelon (the intact 8-foot Hazaj) four times, we will get two variations. In the slow variation, mafa'eelon is pronounced a little slower and more deliberately than usual. We can pronounce 'fa' and 'ee' as longer syllables, taking a short breath between 'Ion' and articulating mafa'eelon, with no harm done to rhythm. In the fast variation, mafa'eelon can be repeated harder and faster, and there would still be no harm done to rhythm. The constant in variations 1 and 2, is the conjunction between 'ma' and 'fa' and the indivisibility of 'mafa'. These specifics are greatly significant in rhythmic speech. (Hossein Jali, 2004)

The rhythm natural to everyday Persian pronunciation today, which is understood and enjoyed by linguists, is the same rhythm of songs and sonnets. In such songs, syllables are not of fixed length and weight, for rhythm to be based on them. It is rhythm that determines whether a syllable is to be pronounced as long or short or whether it even counts. The determining factor, is the specific beat [zarb] in parts of speech. That beat is the stress on a syllable of each word, which the length of syllables depends on. This [syllable] stress and prominence results from a combination of sound intensity and height, ie high pitch. This means prominent syllables are both harder (more stressed) and higher than other syllables. Syllable quantity depends on this prominence; meaning short stressed syllables are more prominent than long unstressed syllables. (Khanlari, 1998)

At present bahr (metre), an expression in Iranian music, means "rhythm" in poetry. Bahr as a prosodic expression, is the rhythmic quality resulting from the repetition or combination of one or more prosodic (metric) scales*.

*Rhythm in music is characterized by a repeating sequence of stressed and unstressed beats (often called "strong" and "weak") and divided into bars organized by time signature and tempo indications. (Wikipedia, 2013)

Prosodic rhythm in poetry shares a long tradition with Iranian festive music. The use of that expression by renowned musicians and musicologists such as Safi-ed-din Ormavi (Safiadin Ormavi/ safi al-din al-urmawi, deceased 694), indicates its common use in Iranian music of old. In the beginning, poetic metre (bahr) was attributed to four-note chords (Tr:thetrachords). According to Abd al-Qadir Maraghi: " Varients of the four-note chord, are called bohour (pl of bahr; metre)." (Maraghi, 1991)

The ancients have described the thetrachord (chaharegan) in a variety of ways that together compose a graph of musical jargon development over time. That was a collection of four successive notes, classified as early soft scales/octave divisions (Maraghe'l, 1991). Safi al-din al-urmawi appears to be the first artist to have defined seven thetrachords. By combining them with the thirteen penachords, he came up with modes called cycles/dowrs (Maraghe'l, 1991), which are in fact the basis for Iranian gamuts.

Every line of poetry consists of words, and each word of several consonants and vowels (letters quiescent or marked with vowel-points). In prosody, rhythm is determined by these vowel-points and quiescent letters. (Khanlari, 1982)

Syllables in the Persian language are a combination of one vowel and two or three consonants. Two types of vowel are distinguishable in that language: the short vowels: a, e, o and the long vowels: a:, e:, u: .

A syllable is a sound with which a letter can be pronounced. For example, when joined, the letters ' $t$ ' and ' $n$ ' make the word "tan". For this word to be uttered, it must be combined with a vowel(s). That means its letters must be marked by the vowel-points and accents a, e, o, a:, e:, u: quiescence and hard-stress marks, for it to be pronounced as a word. For example, "tane" is pronounceable, due to accents and quiescence in the word; the combination of a vowel with one, two, or three consonants is called a syllable.

Syllables come in three forms: short (U), long (-), and protracted (U-). In classical prosody, long and short syllables 
come in the same order in all hemistiches of a poem. The unit of pronunciation like vowels and consonants of the alphabet, is the phoneme (vaaj); and every unit letter is one of the 32 letters of the alphabet. Pronouncing the Persian alphabet involves 29 pronunciation units or phonemes, 6 of which are short and long vowels, and 23 of which are for consonants.

In musical notation, a note is a written sign that represents the frequency of a sound. Every note has duration, beginning with the whole note (semibreve) which is 4 quarter notes long with 0 beat, to the half note (minim) worth 2 beats, to the quarter-note (crochet) worth 1 beat, and down to the quaver and sixty-fourth note. Just as note tension and sound duration are measured, rests are measured. The whole (round) rest equals 4 beats, the half-rest is 2 beats, the quarter-rest is one beat and so forth until the quaver and sixty-fourth note rest. As musical signs for rests are pictorial, there is no unicode for them in Persian text.

There are rhythmic patterns formulated as easy-to-remember words such as (maf'ul, mafa'il, fa'elaton). These words are called pillars/fundamentals and those patterns are called metres or bahr/s (Fatemi, 2003). In antiquity, the science of music was based on cadence (iqa'), because it was with the science of cadence that musical notes and sounds were measured and strung.

\subsection{Cadence}

Cadence in music was as metre (aruz) in poetry. Just as poetical metre consists of metric elements, music consisted of rhythmic cycles (cadence). Cadence has elements such as: guy-wire, peg (foot) and space, each of which have two variations (Table 1) (Maraqe'i, 1987).

Table 1. The elements of cadence

\begin{tabular}{|c|c|c|}
\hline Elements of Cadence & & \\
\hline Guy-wire & Peg & Interval (Space) \\
\hline Stressed-unstressed (strong-weak/saqil khafif) & Joined-spaced (majmu' mafruq) & Short-long (soqra kobra) \\
\hline Tan tan & Tanan Ta:n & Tananan tanananan \\
\hline
\end{tabular}

Musical timing in the past born of a succession of beats. In fact beats were sequenced based on specified time intervals. Rhythm is the firstmost common factor between poetry and music, which in poetry is achieved by a succession of short and long syllables, and in music by a succession of durations such as quarter-note, quaver and semiquaver. (Dehlavi, 2000) Should we assign the duration "semiquaver" to short syllables, "quaver" to long syllables and "quarter-note" to lengthy (keshideh) syllables, a relative musical rhythm can be determined for a poem and its words. The rhythm of the following words is thus demonstrated:

Dana $=(\mathrm{Da} / \mathrm{na})$ long syllable/long syllable

Azadi=(A/za/di) long syllable/long/long

The smallest unit to measure time in the rhythmic system (the system of Iqa'), is "cadence" (naqreh). Naqreh in iqa', is like the letter in poetry. Therefore it is possible to find equivalents for naqreh, in order to put naqreh and iqa' into words and writing, and verbally express musical cadence (iqa'/rhythm). The basis and scale for rhythmic words/chords, is the pattern in which naqrehs are sequenced with their specific time pattern. By sequencing rhythmic elements, successions called rhythmic cycles are produced, which are constantly repeated throughout the piece. In the past, the beat "tan" and its frequency in recurrence, was the popular means of deciding a tune's rhythm. The cycle (dowr) can be considered as rhythm. The rhythmic elements (cadential elements) introduced by Maraqi, are scale words (chords). In the Ekhvan -os-Safa treatise and Farabi's Musiqi-ol-Kabir, the word "tawn" is used in rhythmic blocks (rhythmic elements). Rhythmic words or Atanin are based on the number of letters quiescent and marked with vowel-points. To record cycles, corresponding musical duration can be used. Also, vowels (letters marked with vowel-points) can be demonstrated with a $\mathrm{U}$; and words with vowel-marked and quiescent letters with a -

Table 2, demonstrates the various Atanin: 
Table 2. Various Atanin

\begin{tabular}{|c|c|c|c|c|}
\hline Symbol & Duration & Word Scale & Internal Structure & Element \\
\hline UU & Tana & 2 vowel-accented letters & Stressed (saqil) & Guy-wire \\
\hline-- & Tan & Vowel-accented+quiescent & Unstressed (Khafif) & \\
\hline$--U$ & Tanan & 2 vowel-accented letters+quiescent & Joined (Majmu') & Peg \\
\hline$--U$ & Taana & Vowel-accented+quiescent+quiescent & Spaced (Mafruq) & \\
\hline$-U U-$ & Tanana & 1 vowel-accented+quiescent & Short & Interval (Space) \\
\hline UU--U & Tanananan & 4 vowel-accented+quiescent & Long & \\
\hline
\end{tabular}

Cadence (Iqa') is a question of beat or rhythm. The unit of rhythm in iqa' is naqreh, and the science of iqa' actually means determining the naqrehs' time signature.

Iqa' literally means "charging", "throwing", "capturing someone", "harmonizing melodies and cries" and so forth. But as an expression, it means knowledge of musical rhythm and rules on beats, naqrehs, rests (sokoot/s) and cycles; in other words anything to do with "rhythm". This very word has been used in combinations such as poetic rhythm/cadenceliqa' (oration), tonal rhythm, absolute rhythm, complex rhythm and rhythmic dance (harmonic dance/riyaziyyat-el-iqa'iyyah/harmonic exercise). (Sediq, 2010)

There are two types of rhythm/iqa': conjoined or mawsel iqa'; detached or complex iqa'.

Conjoined iqa' is divided into the four variations: fast hazaj, unstressed hazaj, stressed hazaj and unstressed stressed; and detached or complex iqa' into fast complex, unstressed complex, unstressed stressed and stressed complex. Each comes in three sequences:

First, 2 naqreh + space +2 naqreh

Second, 3 naqreh + space +3 naqreh

Third, 4 naqreh + space +4 naqreh (Sediq, 2010)

Rhythmic elements (elements of cadence) are: Guy-wire, peg and space.

The guy-wire comes in two forms:

1. stressed or strong with two vowel-accented letters, eg "tana", which comprises two naqrehs marked with vowel-points

2. unstressed or weak, which has two letters; one vowel-marked, the other quiescent, eg "tan".

The peg also comes in two types:

1. the joined or adjacent peg, which has three letters: vowel-marked + vowel-marked + quiescent, eg "

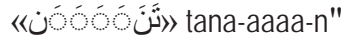

2. the spaced peg, which has three letters: vowel-marked + quiescent+ vowel-marked, eg "ta:na".

Space comes in two forms:

1. small (minor), with four letters: three vowel-marked + quiescent, eg "tananan"

2. large (major), comprising five letters: four vowel-marked + quiescent, eg "tanananan".

Among the different types above, the spaced peg (vatad-e-mafruq) and large space (faseleh kobra) are not often used.

Cadential cycles (rhythmic cycles) are created by the repetition of rhythmic sequences in poetry or music. A rhythmic cycle (dowr-e-iqa'ii) is formed by the succession of chords, based on a specific pattern. By distinguishing notehead colours for percussion instruments, or creating a different accent for beats or naqrehs in a rhythmic cycle, a rhythmic tune (mode) can be produced: Rhythmic mode (maqam)= note-head colour/ accent + rhythmic cycle.

In treatises before Abd al-Qadir, rhythmic cycles were referred to as six-foot cadences or seven-foot cadences or any other names popular with Arab masters of the art; they were known as main or master rhythms. After Abd al-Qadir however, apart from Mohammad Me'ma:r Bana'ii who classed rhythmic cycles as saqa:l, khafa:f and fawa:kht, treatises mainly followed Abd al-Qadir's take on the science of rhythm and cadence. (Sediq, 2010).

Old rhythmic cycles were: primary strong (saqil), secondary strong, weak-strong, strong ramal, ramal, weak ramal, hazaj, fa:khti, major fakhti, median fakhti, minor fakhti.

New rhythmic cycles were those popular with Abd al-Qadir's contemporaries. Those were: Strong (saqil), weak (khafif), four-ply plectrum (chahar-mezrab), original Turkish, fivesome, ramal, hazaj and fakhti.

Five-foot cadences of Abd al-Qadir Maraghe'i: Abd al-Qadir says in Ja:me' ol-Alhan that the penta-cycles are actually 20 cycles, but he refers to 5 of those cylces. Other later treatises also introduce these five cycles: 1. zarb-ol-fat'h (opening beat), 2. shahi (royal), 3. qomriyeh, 4. zarb-ol-jadid (new beat), 5. dowr-e-ma'tin (ma'tin cycle). In treatises, the zarb-ol-fat'h cycle has been introduced as 50 naqrehs and 10 beats, the shahi cycle as 30 naqrehs and 12 beats, the 
qomriyeh cycle as 5 naqrehs and 3 beats, the zarb-ol-jadid cycle as 14 naqrehs and 4 beats, and the ma'tin cycle as 200 naqrehs and 15 beats (Sediq, 2010).

Elements of cadence (rhythmic elements) introduced by Maraghi, are scale words. The ancients noted elements of cadence with letters of expression and later with abjad signs (Arabic alphabetic signs). Today they are expressed as "round note, white note (minim), black note (quarter-note), quaver, etc, and their shapes determine the duration of notes. Some say old rhythms cannot be noted by modern notation techniques. However, should we wish to collate the two, this is how it would look (Khaleqi, 1953): sabab-e saqil/ strong guy-wire (tana), weak guy-wire (tan), vatad-e-majmu'/conjoined peg (tanan), small space/short interval (tananan).

Rhythmic elements (particles) or scale-words, have specific time signatures and are the basis for placing and sequencing naqrehs. By placing rhythmic elements adjacent to one another, a rhythmic cycle (dowr) is formed, which is continuously repeated throughout the piece: naqreh =>element (pillar) =>cycle (dowreh).

Dividing the duration of a piece to equal measures and beats may be the norm today, but it was not so in the past. Musicians of the past had a different way of reading notes. They called rhythm, cadence (iqa'); and instead of measure, there were rhythmic patterns called dowr (cycle). So, cadential cycles meant different rhythmic cycles.

These cycles generally corresponded to one of the poetic rhythms or metric feet. For example, the poetic rhythm "fa'olna fa'oln maf'ulon fa'oln" (in modern notation), would have made a cycle called "ramal-e-saqil/ strong ramal".

However, in order to learn how the dowr (cycle) was noted and taught in olden times, it seems a must to get acquainted to feet in cadence (atanin-e-iqa'ii):

A succession of scales produces the atanin model. Rhythmic scale-words or the atanin, are classed based on their constituent quiescents and vowel-marked letters. The building blocks for scale-words or particles of cadence (rhythmic elements), are the 2 phonemes "t" and "n". To record scales and cycles, scale-words or their equivalent musical duration/traction can be used. Also, vowel-marked letters can be noted with a $U$ and a word with quiescent and vowelmarked letters can be noted with a -. The duration (time-value) of a word with vowel-marked and quiescent letters, is twice that of a word with vowel-marked letters.

Cadential feet (atanin-e-iqa'ii) are used to note rhythms with just the two short and long half-notes with the numeric values 1 and 2, such as quaver and quarter-note. These two short and long half-notes are an imitation of short and long syllables in poetic rhythm and scansion. Every rhythmic unit has at least one long half-note, and the technique is to note that with the long syllable "tan".

So the quarter-note (black note), which will hereafter be considered as a long half-note, will be replaced by the syllable "tan". However, if this long syllable comes after a short syllable, the syllable "nan" will be used. If the half-note of a syllable in a rhythmic unit is short, and this short syllable comes at the beginning of the rhythmic unit, it will be replaced by the short syllable "ta"; and if it comes in the middle of the rhythmic unit, the syllable "na" will be used. Examples will clarify this issue. (Mehrani, 2010).

This following rhythmic figure was known as the first strong (saqil-e-avval):

Tananan tan tananan tanan tanan

The following atanin indicate the ramal-e-saqil dowr (strong ramal cycle):

Tananan tan tan tan tan tan tan tananan tannn

Hereby, several rhythmic figures common in Iranian musical radif (order) are demonstrated by the rhythmic atanin method and musical notation. (Mehrani, 2010).

1. Basteh-negar: tanan tanan

2. Majles afrouz-e-shour: tanann tan

3. Kereshmeh: tnn tnn tnn tn

4. Chahar-pareh: tann tnn

5. Panjeh-mooyeh: tn tn tnn

6. Do ta-yeki: tn tn tn tn tnn tn

In music, "rhythm" is the time-value difference between the notes of a tune. Evidently, the notes' duration must be different (that is, some must be shorter and some longer), for a tune to be sounded. Differences in notes' durations are determined by a specific order, based on the laws of nature. For example, a fast rhythm expresses fast movement, but is short-lived, like the footfall of a charging horse, which sounds three really fast beats and one slow beat.

In films too, charging on horseback is shown to create excitement. On the other hand, when a horse is racing at full speed, it obviously cannot run at the same speed for long. They say: The Arabian horse runs in at full throttle (asb-e tazi do tak ravad be miya:n). When we hear this rhythm, we naturally feel that everything is transient and will come to an end. In gnostic expression, fast rhythm wants to say: "this too will pass". Whereas slow rhythm transmits a feeling of eternity and constancy, like the rhythm of a horse's trot or the ticking of a clock, or the gentle sound of a stream. 
Given the organic union between classical Iranian music and Persian poetry, the above concept is clarified by example, with the following verse:

The lord's wrapped in silk, and us in rugs so rough Fear not, for all souls end in the dust so tough

O cupbearer, of your wine the breath of life, the victor Breath in, bring to life your Victor

(Khajeh dar abrisham o ma: dar gelim A:qebat ey del hameh andar gel-im

Saqia, za:n ba:deh-ye Mansour-dam Dar rag o risheh-ye Mansour, dam)

This sort of poem is called Molavvan (colourful). A molavvan poem is a poem that can be recited with two or more Arabic poetical metres. The same verse can be recited with either of the following rhythms:

Mofta'lon mofta'lon fa'elno or tantatatan-tantatatan-tantatan, which is a fast metric rhythm. A fast poetical metre literally means "fast-moving", and is common to both Persian and Arabic poetry. Its afa'il (rhythmic units) can be extracted by repeating the elements mostaf'elon mostaf'elon maf'ulato. As the name tells, the music based on this metre is overflowing with movement and energy. (Abbasi, 2002)

O cheerful morning breeze, O Saba Thy breath is my Love's aura, marhaba => by Hafez

(Ey nafas-e khorram-e ba:d-e Saba:

-- U U U -- UU -- -- U --

Az bar-e ya:r amade'i , marhaba (well done)) :

-- UU -- -- UU -- -- U -

Mofta'lon mofta'lon fa'elno

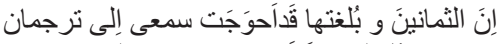

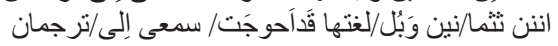

مستفعلن مستفعلن فاعلن مستفعلن مستفعلن فاعلن الثران

Mostaf'alon mostaf'alon fa'olna Mostaf'alon mostaf'alon fa'olna

The ramal meter is a poetical meter common to Persian and Arabic, and its tune and music is created by repeating the element "fa'ela:ton". This meter is mostly used as a hexameter (mosaddas) in Arabic, which means fa'ela:ton is repeated 6 times. In Persian poetry however, it is used as a "mosaddas" or "mosammen" (8-foot) meter. Some say ramal is the sort of music produced by this rhythm (meter); and some call it ramal, because pegs are sounded amidst guy-wires. This rhythm for love, makes for music that is light (khafif) and gentle, with a tune that is emotional and melancholy. Some researchers find it suitable for the purpose of singing, reflection and contemplation. (Abbasi, 2002)

"Hear from the flute, its tale to tell" (Beshno az ney, choon heka:yat mikonad), is pronounced with a ramal rhythm, and scans as:

Fa'ela:ton fa'elaton fa'elno, or tan tatan tan-tan tatan tan-tan tatan.

If this poem is recited with fast rhythm and strong beat, it will convey this meaning: It is true that as Hafez says, "Destiny gives the ignorant the reins to all that humans desire. But that even this is temporary; soon we will all be buried and must therefore prepare for the other world too."

But when recited with gravity, in the ramal metric, the verse "Hear from the flute..." conveys constancy and eternity. I $t$ wants to say: Things have always been as such, and will be as such for as long as they are (Safvat, 2007).

Fortune gives glory, fortune strips of pride

It is the wheel of fortune that decides the tide

(Roozega:r ast i:n ke gah ezzat dahad gah kha:r da:rad

Charkh-e ba:zigar az i:n ba:zi:che-ha besya:r da:rad)

(--U-- -- -- U -- -- -- U -- -- -- U-- --

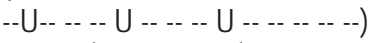

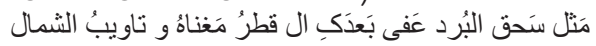

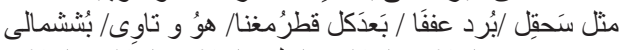

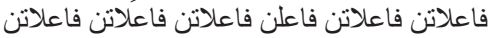

Fa'elaton fa'elaton fa'elon fa'elaton fa'elaton fa'elaton

Aye, it's all about difference within rhythms, not rhythm itself. In other words, the less the difference between particles of a rhythm, and the slower the tune, the more its introversion. On the contrary, the more the difference, the more the extroversion.

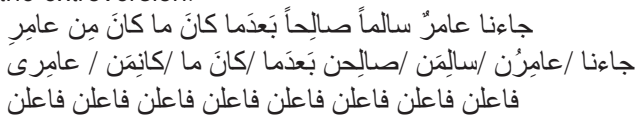

Fa'elon fa'elon fa'elon fa'elon fa'elon fa'elon fa'elon fa'elen

In the eighth and ninth centuries hijirah, when music reached its peak in the Islamic era, tunes were divided into 
two general groups: rhythmic and arrhythmic. A rhythmic tune was played with a rhythmic cycle (cadential cycle), and the story is based mainly on this kind of tune. Although arrhythmic pieces (ra:h/route(s)) are sometimes played at the same time. Second is the arrhythmic tune, also called "nava:kht" (strike/beat), which the ra:h or route is based on.

\section{Conclusion}

For the words of a poem to form a bond with music, they must be easily understood upon being heard. A composer must not only consider the sound quality of his instruments and their sonic compositions; but must also consider the quality and quantity of syllables, and logic of the lyrics. Especially with operatic compositions, when the language must be both simple and sans simile and metaphor, so that combining it with music, does not add to its complexity and incomprehensibility. Just as a poem by itself is touching, its melody should be independently musically expressive. This way, when played on a musical instrument without its poem and lyrics, it can still be fully musically expressive. Music is of two categories: "the melodic mode/class" (ba:b-e alhan) and the "cadence mode" (ba:b-e iqa'), which in Latin are referred to as "tones of melody" and "rhythmic cadence". Cadence is the percussion sound of the drum and orchestral drum and other rhythmic instruments; and the melodic strain is that which is sounded by vocal chords and [string] instruments.

Cadences were used in a different fashion, in poetry; as the rhythmic sounds "tan tanan tananan" or "mofa'elon fa'olna mofta'elna" and their combinations. Persian [poetic] metre derives from the Iranian musical disposition. Abd alQadir Maraghi (9th C. Hijirah) has left behind reliable documents on cadence, in Jame'-ol-Alhan (A Comprehensive Account on Melodies), Maqasid-ol-Alhan (Meaning of Melodies) and Sharh-e-Adwar (Statement on Cycles). By studying Abd al-Qadir Maraghi, it is easily seen that rhythm in Iranian music, is due to rhythmic speech or Persian poetry. Ancient musicologists contributed their musical theory on cadence, based on elements of cadence (cadential elements), that are actually the meeting point between metric rhythm and musical rhythm. Therefore, in analyzing poetry-specific literature, the researcher must not only apply semantics to decipher message content and general and minute word meanings. But he must also apply the science of music, which observes the structure of poems. The structure of Persian poems is like the strings of the tar, setar and harp. When recited they vibrate, creating music in the reciter's mind, and causing an upheaval within his very being. In this way, the inner music of a Persian poem can by itself make its reciter experience a complete mood-swing; it can make him happy or sad, intoxicated or sober, eager or impatient. It can turn his melancholy mood to joyful.

\section{References}

Mehrani, H. (2011). Book of songs (Ketab-e-sorayesh). (2nd ed). Tehran.

Fatemi, S. (2004). Childish rhythm in Iran (Ritm-e koodakaneh dar Iran). Mahoor Publishing Co.

Shahmiveh Esfahani, G. (2004). The art of chanting (Honar-e talavat).

Mohammadzadeh-ye Siddiq, H. (2011). A trip through musical theses (Seyri dar resale-haye musiqiyayi). 1 $1^{\text {st }}$ Edition. Soore-ye Mehr Publishing Co.

Jalli, H. (2005). Musical measure in poetic rhythm (Mizan-e musiqiyayi-ye vazn-e she'r). Vol. 2. Samarqand Publishing Co.

Mousavi, S.A. (2005). An account/commentary on Safi al-Din al-Urmawi's Cycles (Sharh al-Adwar: Safi al-Din al-Urmawi) . 1st Edition. Soore-ye-Mehr Publishing Co.

Maraghi, A.Q. (1988). Jami al-Alhan (Arabic for Encyclopedia of Music). Effort by the late Taqi Binesh-Pazhouh. Tehran.

Abbasi, H. (2003). Rhyme and metre (Arouz-o-qafiyeh). $1^{\text {st }}$ Edition. Tehran.

Safvat, D. (2008). Philosophy of music (Falsafe-ye musiqi). 2nd Edition. Nik Publishing Co.

al-Maraghi A.Q. Ghaybi (1992). Commentary on cycles (Sharh al-Adwar). Tehran: Printed by Taqi Binesh.

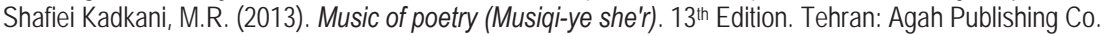

Shafiei Kadkani, M.R. (2011). Archetypes of illusion in Persian poetry (Sovar-e khial dar she'r-e Farsi). 15th Edition. Tehran: Agah Publishing Co.

Natel Khanlari, P. (2008). Rhythm in Persian poetry (Vazn-e she'r-e Farsi). $7^{\text {th }}$ Edition. Tehran: Tus Publishing Co.

Natel Khanlari, P. (1999). Seventy sayings (Haftad sokhan), Vol. 1: Poetry and art. $2^{\text {nd }}$ Edition. Tehran: Tus Publishing Co. 